\title{
Closing the extension gap: Information and communication technology in sustainable agriculture
}

Survey results suggest that time constraints, technical complexity and the potential for misinformation are barriers to the adoption of information and communication technology tools among extension professionals.

by Mark Lubell and Neil McRoberts

\section{Abstract}

As the information revolution sweeps through the agricultural sector, extension professionals may be lagging behind their clients in the use of information and communication technology (ICT) such as social media, which could be a valuable tool for outreach and education. We surveyed sustainable agriculture stakeholders in California — extension professionals, county agricultural commissioners, and members of farm bureaus and producer groups - to measure their ICT behavior and attitudes. Drawing on diffusion of innovation theory, we characterized the innovation attributes of ICT that may influence the adoption and use of new technology among extension professionals. We also studied their demographic characteristics to establish whether there was a connection with ICT use. The main perceived benefit of ICT was that it can quickly reach larger, more diverse and more distant audiences. The perceived challenges included lack of professional support, the potential for misinformation on social media platforms, and the time requirements and technical complexity of technology use. Extension professionals experienced these challenges more than other sustainable agriculture stakeholders, creating a technology gap between extension professionals and their clientele. An ICT community of practice and clear organizational guidelines for measuring and reporting performance relating to ICT might help extension professionals close the gap.
armers and other agricultural stakeholders are experimenting with many types of information and communication technology (ICT) such as websites, blogs, social media and mobile decisionsupport applications. As data scientists integrate ICT with "big" data, farmers can downscale diverse sets of information for local decision-making and upscale local data to see emergent patterns at multiple scales. Social media tools allow extension professionals, farmers and other agricultural stakeholders to communicate in new ways about the broad range of issues affecting agroecological systems. The increasing use of ICT in agriculture has engendered a significant debate about its benefits for achieving extension goals relative to its potential risks and costs.

This paper empirically examines ICT use among extension professionals working on sustainable agriculture in California. We broadly define "extension professionals" as professionals engaged in agriculture outreach and extension, either based at a university (e.g., Cooperative Extension specialists, university faculty, county agents)

or elsewhere throughout

Online: https://doi.org/10.3733/ca.2018a0025
New research findings on agricultural stakeholders use of information and communication technology (ICT) - websites, blogs, social media and mobile apps — indicate that UC employees used fewer ICT platforms and used social media less frequently than other professionals in the field of agriculture outreach and extension. 
the food system and agricultural knowledge networks (e.g., consultants, members of nongovernmental organizations such as county farm bureaus and producer associations). We particularly emphasize the role of social media platforms such as Twitter, Facebook and LinkedIn as innovative extension tools for building knowledge networks, coordination, communication, outreach and education.

We draw on diffusion of innovation theory as a framework that can integrate many elements of the debate about the benefits and risks of ICT (Feder and Umali 1993; Prokopy et al. 2008; Rogers 2010). Diffusion of innovation theory suggests that ICT adoption depends on how extension professionals perceive the attributes of this innovative technology, such as its relative advantage over other extension tools and its complexity. We also examine how demographic characteristics of extension professionals influence ICT adoption. Our analysis sheds light on the potential technology gap, hinted at by extant research, between extension professionals' use of ICT and the general public's, and possibly agricultural clientele's, greater use of ICT. Developing policy recommendations to improve the appropriate use of ICT requires identifying the critical barriers to ICT adoption among extension professionals.

Our research has implications for broader ideas about how to adapt extension systems to the new realities of agricultural knowledge networks and innovation systems (Klerkx et al. 2010; Klerkx et al. 2015; Klerkx and Proctor 2013; Lubell et al. 2014). Modern agricultural knowledge networks are distributed systems, where relevant information is developed and communicated by a wide range of stakeholders.

The traditional top-down model of delivering landgrant university research to local clientele is becoming obsolete, especially when resources are thin (Carr and Wilkinson 2005). It must be complemented by a more bottom-up model, where in addition to developing and broadcasting new knowledge, land-grant universities and other extension organizations must build innovation systems that coordinate knowledge networks among different stakeholders (Lubell et al. 2014). Such networks seek to synergistically combine social, technical and experiential learning. New ICTs are potentially important tools in this endeavor, especially when used to complement other methods of outreach and education. The results of this paper enhance the evidence base for this endeavor.

\section{An extension technology gap?}

The information technology revolution has transformed the way that people access information and build social connections (Barabasi 2003; Rainie and Wellman 2012; Watts 2004) across the globe. The latest survey results from the Pew Research Center (2016) estimated that the percentage of U.S. citizens using at

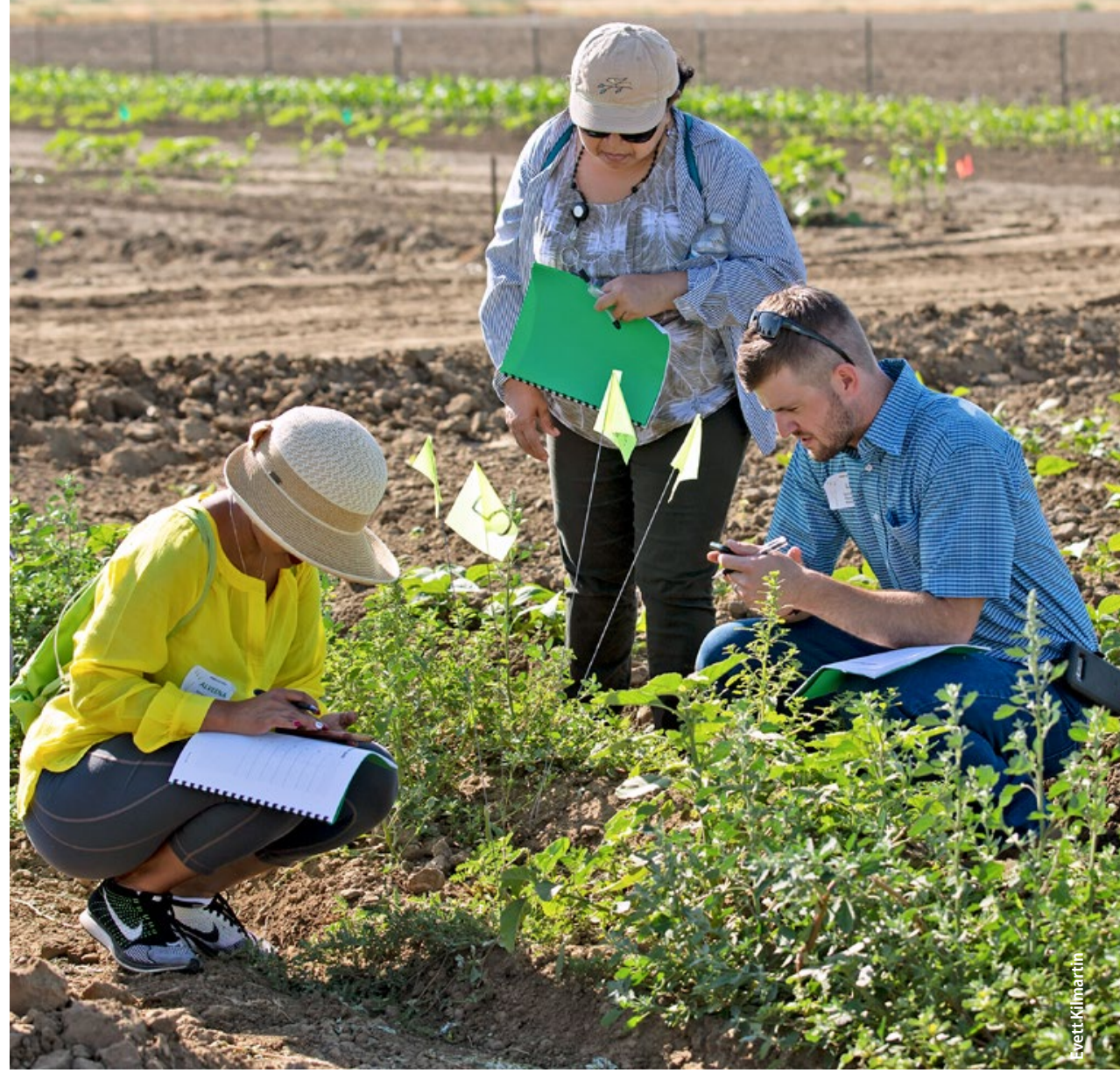

The traditional top-down model of delivering landgrant university research to local clientele is becoming obsolete, especially when resources are thin. New ICTs are potentially important tools in this endeavor, especially when used to complement other methods of outreach and education.
States had computer and internet access and $47 \%$ used computers for farm business. Computer and internet usage was higher among wealthy farmers. A study in the Pacific Northwest (Guenther and Swann 2011) found that potato growers used popular ICT platforms as frequently as college students - $93 \%$ of growers used email compared with $97 \%$ of students; $97 \%$ of growers used text messages compared with $94 \%$ of students; $70 \%$ of growers used Facebook compared with $73 \%$ of students; and $90 \%$ of growers used YouTube compared with $91 \%$ of students - and growers overall used 3.5 more varieties of technology than college students. In developing countries, mobile phone technology continues to expand and provides a crucial information and networking resource for rural agricultural populations (Aker 2011; Matous et al. 2011; Matous et al. 2015; Matous 2017).

Despite some evidence that extension clientele are using ICT at rates approaching those of the general population, extension professionals may be lagging behind both groups. Gharis et al. (2014) reported that among participants in a Natural Resources Conservation Service webinar, 53\% used Facebook 
Despite some evidence that extension clientele are using ICT at rates approaching those of the general population, extension professionals may be lagging behind both groups. and 10\% used Twitter. O’Neill et al. (2011) found that the proportion of members of the financial services community of practice for e-Extension using Facebook (42\%) or Twitter (7\%) daily is far less than the general population. While the existing research hints at a potential technology gap in extension professionals' use of ICT, much more research is needed to document and explain ICT adoption and use within agricultural systems.

The potential gap in extension professionals' use of ICT reflects a lively ongoing debate about the costs, benefits, barriers and risks of ICT for agriculture (Fuess 2011; Gharis et al. 2014; Newbury et al. 2014; Seger 2011). On the benefits side, ICT may provide access to information, coordination, job opportunities, social networks and improved services (Aker 2011). Extension professionals expect ICT to create a snowball effect (Cornelisse et al. 2011), with information more quickly reaching a larger and more diverse audience than inperson communication methods like workshops and field meetings (Gadino et al. 2016). The benefits may include the integration of real-time information into mobile applications or websites to provide decision support, linking daily agricultural decisions to economic and agro-ecological processes at multiple scales.

Realizing these benefits requires overcoming many potential risks, barriers and costs. Gadino et al. (2016) highlighted the importance of linking traditional inperson methods with digital technology and the time required to update ICT with new and real-time information. Newbury et al. (2014) identified the barriers as lack of training, concern about information control and time availability. Gharis et al. (2014) emphasize lack of professional acceptance by colleagues as a barrier to innovation, which is linked to the capacity to measure effectiveness. O'Neill et al. (2011) pointed out the need for organizational procedures; only $29 \%$ said their institutions had guidelines for reporting, and only $22 \%$ of their respondents reported their own social media outreach activities to their extension administration. There was a notable amount of uncertainty $-27 \%$ of nonreporters said they did not know how to use social media, and 38\% did not know if their institution had guidelines.

\section{Diffusion of innovation theory}

Existing research lacks a theoretical framework to integrate the diverse terms of the debate about ICT adoption among extension professionals. Diffusion of innovation theory, which examines how innovations spread through a population of users, provides such a framework. It has been an enduring research topic in agricultural decision-making for more than a century (Feder and Umali 1993; Prokopy et al. 2008; Rogers 2010; Ryan and Gross 1947; Wejnert 2002). A central argument of diffusion theory is that the likelihood of an innovation being adopted is related to the following attributes of the innovation: relative advantage, compatibility, complexity, trialability and observability. We used these attributes to frame our research hypotheses.

"Relative advantage" refers to the innovation's potential benefits and opportunities relative to other extension tools. For ICT, the most frequently discussed advantages are its capacity to reach larger, more diverse and more geographically dispersed audiences (Aker 2011; Cornelisse et al. 2011; Gadino et al. 2016). Also, ICT can quickly deliver new information, potentially in real time with linkages to large-scale data. ICT may also provide support for on-the-ground decisions, for example, about agriculture management, or for coordinating the activities of extension professionals.

"Compatibility" is the extent to which the innovation is compatible with professional and social norms. For extension, an important norm is delivering scientifically valid and neutral information to support decision-making and stakeholder dialogue. Especially with the everyday mention of "fake news" and "internet trolls," extension professionals worry that social media may facilitate the spread of misinformation and provide an avenue for unreasonable individuals to corrode civic dialogue. In addition, many extension professionals feel that relative to more traditional outreach and publication strategies, there is a lack of professional incentives and peer recognition for the use of ICT.

"Complexity" refers to the difficulties of integrating the innovation. In terms of the ICT debate, not all extension professionals have the technical knowledge to effectively use social media platforms or effectively integrate communication across multiple platforms. It may take too much time to learn how to use social media and maintain an active web presence. These complexities are exacerbated by a lack of widely recognized best practices about how to effectively craft social media communication.

"Observability" and "trialability" refer to the extent to which the innovation's effectiveness can be observed and tracked. There is a lack of clarity about how to track the effectiveness of ICT, for example, observing who accesses and uptakes information posted on Facebook or Twitter (Gharis and Hightower 2017). This includes the use of altmetrics, since there is no universally accepted method of measuring social media effectiveness and no clear policies from the University of California, UC Agriculture and Natural Resources, or other organizations. Furthermore, it is more difficult to control access to or target the audience for social media information with the same precision as in-person strategies aimed at particular constituencies.

\section{ICT use study}

We studied ICT use among extension professionals involved in sustainable agriculture in California. An empirical study, it analyzed whether ICT adoption and use was affected by perceptions about ICT (the innovation attributes described above) and the professional 
demographics of the individual user. The data came from 661 respondents to a statewide survey fielded between May and July 2016, which achieved an overall response rate of $28 \%$ (see technical appendix, http://ucanr.edu/u.cfm?id=214).

In addition to UC Cooperative Extension professionals, the survey included people from organizations that are part of the knowledge network engaged in outreach, education and communication: producer groups, nongovernmental organizations, consultants, resource conservation districts, government agencies and others. While some respondents did manage farms, we were not targeting farmers but rather those who develop and deliver information to farmers. It would be useful for future research to extend the survey to farmer populations, specific consultant groups such as pest control advisors, and agricultural knowledge networks in other countries and U.S. states.

Using the framework of the diffusion of innovation theory, our analysis tested the following hypotheses: extension professionals who perceive a greater relative advantage are more likely to adopt ICT; less likely to adopt ICT are extension professionals who perceive ICT as incompatible with their values and social norms, extension professionals who perceive ICT as too complex or time consuming and extension professionals who are uncertain about how to measure ICT effectiveness or strategically target audiences.

In addition, we tested how demographic factors may be linked to ICT adoption, with the expectation that the patterns would be similar to the patterns in the general population. To pursue the possibility of an extension gap, we tested whether UC employees had a lower ICT adoption rate relative to other types of extension professionals.

\section{Survey, analysis models}

We tested our hypotheses by first constructing dependent variables for the number of ICT platforms used and the frequency of social media use. The survey assessed ICT adoption by asking respondents if they used blogs, websites, email, mobile applications, Facebook, Twitter, Pinterest, Instagram or LinkedIn to communicate or learn about sustainable agriculture. We constructed a yes/no variable for each ICT platform.

To zero in on the frequency of use for just the social media platforms (Facebook, Twitter, Pinterest, Instagram and LinkedIn), we followed the Pew Internet Survey in establishing the following categories of use: several times a day, once a day, a few days a week, every few weeks, or less often. Importantly, the focus was on using social media for professional communication about sustainable agriculture, not personal use of social media.

To analyze how perceptions about the attributes of ICT are related to ICT behavior, we constructed a social media frequency scale that calculated the average frequency of social media use across all five platforms, plus an "other social media" category. The scale ranged from $1=$ do not use any social media to $6=$ use all social media several times per day, with mean $=2.01$. To calculate the number of total ICT platforms used, not just the social media platforms, we summed the number of platforms respondents checked; the numbers ranged from 0 to 9 , with mean $=3.81$.

We then estimated multivariate models with social media frequency (ordinary least squares regression) and total number of ICT platforms (Poisson regression) as dependent variables, and the four attributes of innovations (relative advantage, compatibility, complexity, and observability and trialability) as independent variables (see technical appendix for survey wording and descriptive results for innovation attributes). Respondents' perception of social media's relative advantage was measured by averaging their responses to six statements related to its capacity to reach audiences and help extension professionals coordinate professional activities. These statements form a reliable scale (Cronbach's alpha $=0.84$ ) ranging from $1=$ strongly disagree on all statements to $5=$ strongly agree on all statements, with mean $=3.71$.

Respondents' perception of compatibility was measured in their responses to four statements: social media risks spreading fake news, there are positive incentives for its use, most colleagues use it, and it involves too much interaction with trolls. The response options did not form a reliable scale, so we included each statement as a separate variable in the analysis.

Perception of social media complexity was measured in responses to these four statements: it takes too much time, it's technically difficult to use, best practices are well known, and the large number of platforms is confusing. Again, the response options did not form a reliable scale, so we included each statement as a separate variable in the analysis.

Lastly, respondents' perception of the measurability (or observability and trialability) of social media's effectiveness was assessed. One statement suggested it was easy to measure effectiveness; the other statement suggested it was easy to identify appropriate audiences for social media. Responses were averaged into a reliable scale (Cronbach's alpha $=0.74$ ) that ranged from $1=$ strongly disagree on both statements to $5=$ strongly agree on both statements, with mean $=2.32$.

To test the effect on ICT adoption of users' demographic characteristics, we used the same dependent variables as described above, and we estimated the same models using the following demographic independent variables: sustainability attitude (five-point Likert scale; $1=$ sustainability deserves much less emphasis, $5=$ sustainability deserves much more emphasis), age (mean $=53.2$ ), income (eight-category scale ranging from less than $\$ 25,000$ to $\$ 200,000$ or more household income before taxes in last 12 months; modal category was $\$ 100,000$ to $\$ 149,000$ ), UC system (dummy variable indicating employees of UC or UC Agriculture and Natural Resources), male (dummy variable; 1 $=$ male, $0=$ female/other) and education (seven-category scale ranging from did not graduate high school to advanced degree; modal category was advanced degree - M.A., M.D., Ph.D.).

\section{Patterns of ICT use}

Figure 1 reports the overall adoption rates for the ICT platforms. In decreasing order of use, email was used by $92 \%$ of the respondents, followed by websites ( $80 \%$ ) and Facebook (58\%), with Instagram and Pinterest having the lowest adoption rates. While the results for the most popular platforms echo the results for the general population, Twitter (37\%) and LinkedIn (51\%) were used relatively more by extension professionals because they are specifically intended for information dissemination and professional networking.

Figure 2 reports the average temporal frequency indicated by each respondent for using just social media. For the general population, Pew reports that $55 \%$ of Facebook users and $23 \%$ of Twitter users access their accounts several times per day. In contrast, our sustainable agriculture stakeholders in California access Twitter and Facebook at the lower rates of once a day or a few days per week. The lower frequency of use for LinkedIn most likely reflects that the content (professional profiles and events) changes more slowly than the events communicated on Twitter and Facebook. 
Figure 3 plots the coefficients (see technical appendix for full model results) from an ordinary least squares regression model for social media frequency and a Poisson model for number of ICT platforms (a count variable), with the variables arranged in order of decreasing magnitude from the social media frequency model. Relative advantage had the strongest positive relationship with both the frequency of social media use and number of ICT platforms. Respondents who thought most of their colleagues used social media also used more ICT platforms, more frequently.

Technical difficulty and concern about trolls had negative effects in both models. Interestingly, the attributes of innovations were less important for the number of ICT platforms used than for the frequency of social media use, where the capacity to measure effectiveness and identify the audience had a positive influence and lack of time and concern about fake news had strong negative effects. The existence of professional incentives, confusion about the number of platforms

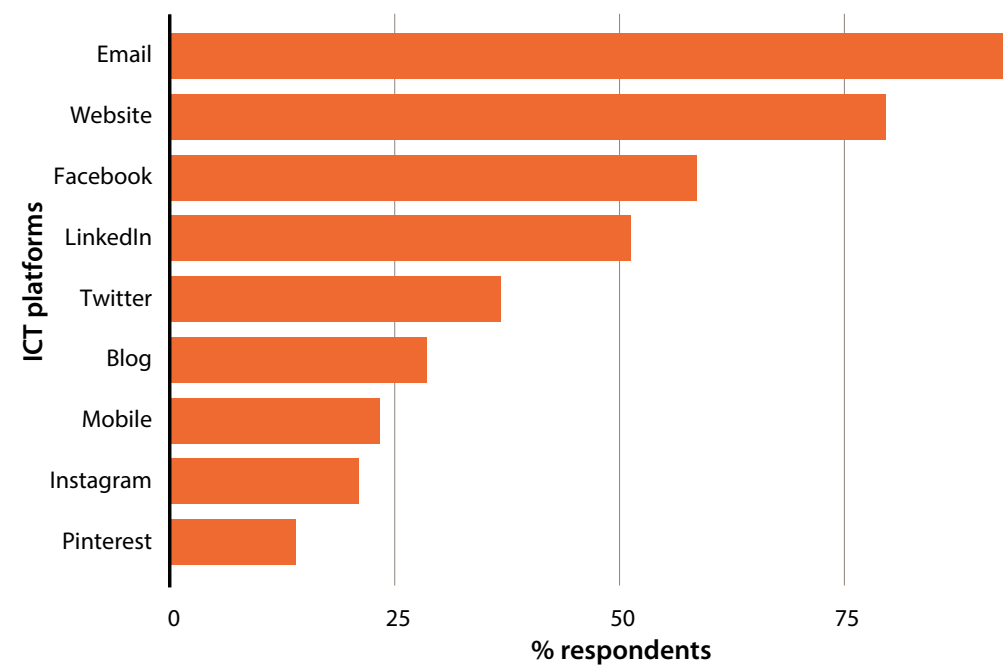

FIG. 1. Which of the following information and communication technologies, if any, do you use in your professional responsibilities?

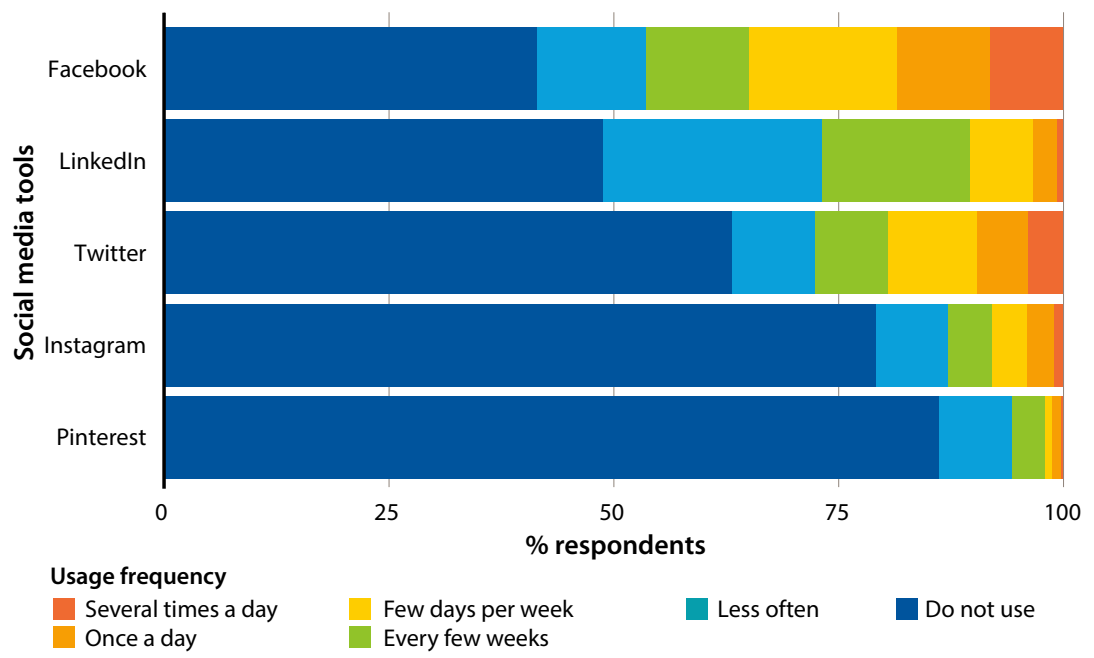

FIG. 2. How frequently do you use the following social media tools to communicate or learn about sustainable agriculture? and knowledge about best practices were unimportant in both models.

Figure 4 suggests some demographic variables behaved in ways consistent with the general population: ICT and social media use was higher among female, younger and wealthier respondents. The results also corroborated the technology gap described earlier: UC employees used fewer ICT platforms and used social media less frequently than other respondents. More educated respondents also used social media less frequently, which contrasts to the general population, where educational levels are positively correlated with social media use.

In the context of professional extension activities, UC system employees or those with advanced degrees may be stressed for time, perceive social media as incompatible with norms of scientific knowledge sharing or lack professional incentives. The breakdown of UC respondents was $35 \%$ campus faculty, $13 \%$ Cooperative Extension specialist, 22\% Cooperative Extension county advisor, $6 \%$ other academic title, $10 \%$ student/ postdoctoral scholar, $11 \%$ staff and $3 \%$ other.

\section{Communities of practice}

Sustainable agriculture stakeholders in both developed and developing countries are quickly catching up to the information revolution that has transformed society in the 21 st century. Our results confirmed the usefulness of diffusion of information theory, which frames the debate about the benefits and risks of ICT in terms of innovation attributes related to relative advantage, compatibility, complexity, observability and trialability. Extension professionals clearly recognized the relative advantages for ICT in terms of quickly communicating with a more diverse and distant audience, but with less potential to coordinate on-the-ground activities. Extension professionals are more likely to capitalize on these relative advantages if their colleagues are also using ICT, and they have good tools for measuring effectiveness. The most important barriers for widespread adoption of ICT were time constraints, technical complexity and incompatibility between norms of scientific discourse and the reality of trolls and misinformation on the internet.

These results support some concrete recommendations for organizations seeking to increase the use of ICT and make it more effective for extension professionals. Resources could be invested in developing a community of practice for aspiring ICT users interested in using ICT for outreach, with leadership from extension professionals with an established reputation for successful innovation. Communities of practice are one of the organizational concepts in e-eXtension, and are defined as informal networks of professionals with a common goal who regularly interact to share information and expertise (Wenger and Snyder 2000). They can help creatively solve problems, transfer knowledge and develop professional skills and are effective where 
the network of individuals is distributed across many administrative units or system components, as is the case with extension professionals experimenting with ICT.

A sponsoring organization can help foster a community of practice by identifying potential members, providing organizational infrastructure for interaction and measuring effectiveness with appropriate metrics. Such a community of practice should document the potential advantages of ICT and provide information about best practices. It would increase awareness about how many extension professionals are using ICT, which would help create a community norm. The community of practice should include a diverse set of stakeholders, including digital technology specialists from outside of agriculture who are knowledgeable about different types of tools, altmetrics and social media strategies that are effective in digital communication.

It is also important for agricultural extension organizations, including land-grant universities, to establish clear guidelines for recognizing the value of ICT as an extension tool that complements traditional communication strategies and ways of extending knowledge. If extension professionals know what counts in terms of documenting their professional activities for job performance evaluation, they are less likely to be confused and view ICT as a risky endeavor. Developing such guidelines would benefit from consultation by

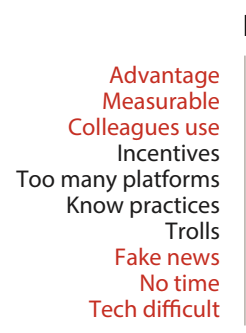

\section{Frequency of social media use}

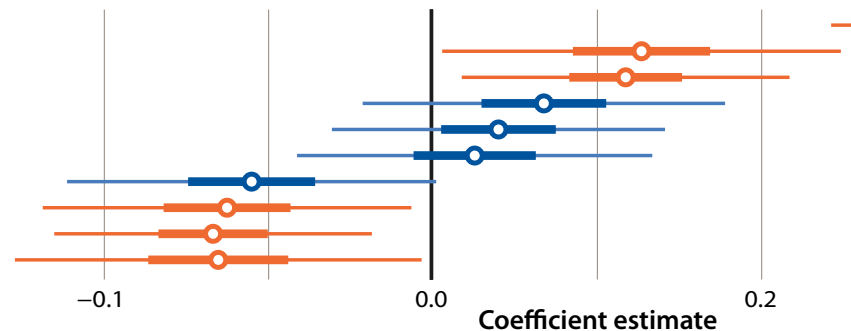

Coefficient estimate

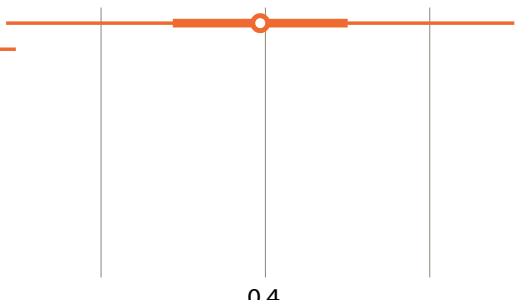

0.4

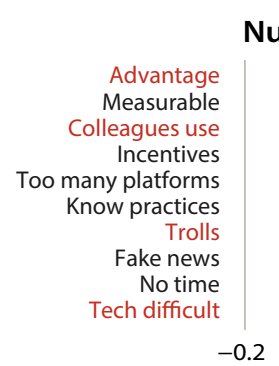

$-0.2$

Number of ICT platforms used

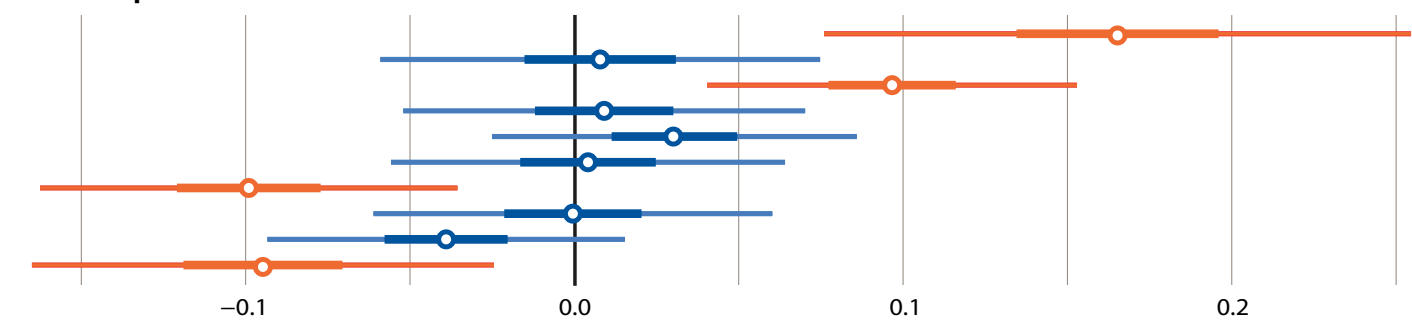

Coefficient estimate

FIG. 3. Coefficient plots for innovation attribute regression model results. Each bar displays the coefficient estimate (bold dot) and the 50th (thick lines) and 95th (thin lines) percentile confidence intervals from the regression models. Any coefficient estimate below zero represents a negative correlation with the dependent variable, and above zero represents a positive correlation. The orange lines indicate coefficient estimates where the $95 \%$ confidence interval does not contain zero, which are statistically signficant at the $p<0.05$ level according to standard null hypothesis tests.

\section{Effect of demographics on frequency of social media use}

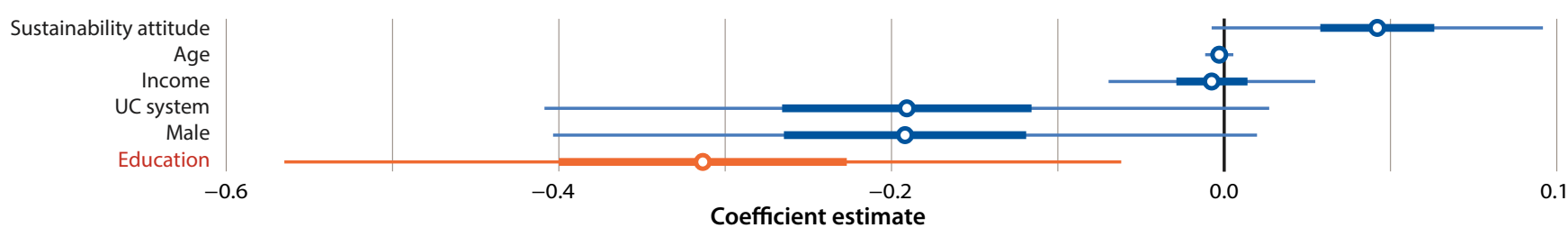

Effect of demographics on number of ICT platforms used

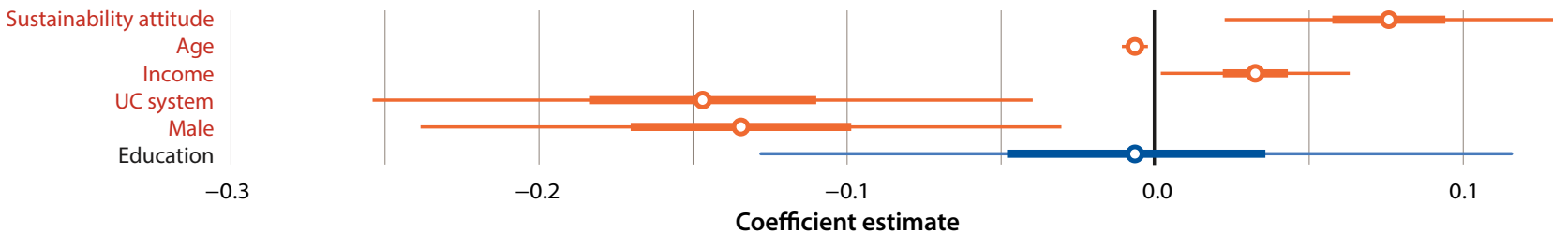

FIG. 4. Coefficient plots for demographic regression model results. Each bar displays the coefficient estimate (bold dot) and the 50th (thick lines) and 95 th (thin lines) percentile confidence intervals from the regression models. Any coefficient estimate below zero represents a negative correlation with the dependent variable, and above zero represents a positive correlation. The orange lines indicate coefficient estimates where the $95 \%$ confidence interval does not contain zero, which are statistically signficant at the $p<0.05$ level according to standard null hypothesis tests. 
outside specialists with expertise in digital tools and measurement.

The risks of misinformation and credibility may be some of the most important for extension organizations to address at a strategic level. Such organizations typically desire to be perceived as impartial providers of evidence-based information. Social media platforms recognize that legitimate knowledge exists outside of Cooperative Extension but also provides a gateway for misinformation. At the individual level, the risk is not so much that a particular extension professional may make a mistake in communicating their own research, but rather they may unintentionally spread misinformation from others and be required to invest additional resources in sorting accurate social media information from misinformation. At the institutional level, social media's democratization of information creates the fear of messages being corrupted, misinterpreted or simply lost in the wash of real information and misinformation. In both cases, it is important to avoid damaging the reputation of providing high-quality science communication.

However, Bastos et al. (2018) provide some evidence that may mitigate these fears. Examining the topology of Twitter networks connected with UC Agriculture and Natural Resources Twitter users, Bastos et al. (2018) found that communities focused on specialized agricultural topics formed centralized networks in which a relatively small number of expert nodes collected and broadcast information to a large audience. In other words, relative to more general users and nonspecialists, technical experts become more central in the online networks and serve as important information hubs for specialized and technical issues. This suggests that social media communication is not completely incompatible with the traditional extension goal of providing hubs of expertise.

Further research is needed to increase confidence in our results and recommendations. More systematic comparison between extension professionals and their clientele would corroborate the extent and nature of the technology gap. While our findings are relevant for extension professionals involved in sustainable agriculture, it would be important to generalize the research to other types of agricultural sectors, compare different commodity groups, directly survey farmers and extend the research to natural resource managers. Using big data approaches to monitor the dynamics and effectiveness of communication is also an important effort going forward. CA

M. Lubell is Professor, Department of Environmental Science and Policy, UC Davis, and N. McRoberts is Associate Professor, Department of Plant Pathology, UC Davis.

\section{References}

Aker JC. 2011. Dial "A" for agriculture: A review of information and communication technologies for agricultural extension in developing countries. Agr Econ 42(6):631-47

Barabasi A-L. 2003. Linked: How Everything Is Connected to Everything Else and What It Means. New York: Basic Books.

Bastos M, Piccardi C, Levy M, et al. 2018. Core-periphery or decentralized? Topological shifts of specialized information on Twitter. Soc Networks 52:282-93.

Carr A, Wilkinson R. 2005. Beyond participation: Boundary organizations as a new space for farmers and scientists to interact. Soc Natur Resour 18(3):255-65. https://doi.org/ 10.1080/08941920590908123

Cornelisse S, Hyde J, Raines C, et al. 2011. Entrepreneurial extension conducted via socia media. J Extension 49(6):6.

Feder G, Umali DL. 1993. The adoption of agricultural innovations: A review. Technol Forecast Soc 43(3/4):215-39.
Fuess LC. 2011. An analysis and recommendations of the use of social media within the Cooperative Extension system: Opportunities, risks, and barriers. Cornell University Honors Thesis. https://hdl.handle. net/1813/23129

Gadino AN, Brunner JF, Chambers U, et al. 2016. A perspective on the extension of researchbased information to orchard management decision-makers: Lessons learned and potential future directions. Biol Control 102:121-7.

Gharis LW, Bardon RE, Evans JL, et al. 2014. Expanding the reach of extension through social media. J Extension 52(3):3

Gharis LW, Hightower MF. 2017. A practical method for collecting social media campaign metrics. J Extension 55(2):2.

Guenthner JF, Swan BG. 2011. Extension learners' use of electronic technology. J Extension 49(1):1.

Klerkx L, Álvarez R, Campusano R. 2015. The emergence and functioning of innovation intermediaries in maturing innovation systems: The case of Chile. Innov Develop 5(1):73-91.
Klerkx L, Noelle A, Leeuwis C. 2010. Adaptive management in agricultural innovation systems: The interactions between innovation networks and their environment. Agr Syst 103(6):390-400. https://do org/10.1016/j.agsy.2010.03.012

Klerkx L, Proctor A. 2013.

Beyond fragmentation and disconnect: Networks for knowledge exchange in the English land management advisory system. Land Use Policy 30(1):13-24.

Lubell M, Niles M, Hoffman M. 2014. Extension 3.0: Managing agricultural knowledge systems in the network age. Soc Natur Resour 27(10):1089-103.

Matous P. 2017. Complementarity and substitution between physical and virtual travel for instrumental information sharing in remote rural regions: $A$ social network approach. Transport Res A-Pol 99 (May):61-79. https://doi.org/10.1016/j. tra.2017.02.010

Matous P, Todo Y, Pratiwi A. 2015. The role of motorized transport and mobile phones in the diffusion of agricultural information in Tanggamus Regency, Indonesia. Transportation 42(5):771-90.
Matous P Tsuchiya T, Ozawa K. 2011. Farmers' access to resources via networks in remote rural areas with mobile phone reception: Creating a resource battery for a mountain tribe in South India. Rural Soc 20(2):174-86. https://doi. org/10.5172/rsj.20.2.174

Newbury E, Humphreys L, Fuess L. 2014. Over the hurdles: Barriers to social media use in extension offices. J Extension 52(5):5.

O'Neill B, Zumwalt A, Bechman J. 2011. Social media use of Cooperative Extension family economics educators: Online survey results and implications. J Extension 49(6):6.

Pew Research Center. 2016. Social Media Update

2016. www.pewinternet. org/2016/11/11/social-mediaupdate-2016/\#usage-anddemographics-of-social-mediaplatforms

Prokopy LS, Floress K, KlotthorWeinkauf D, Baumgart-Getz A 2008. Determinants of agricultural best management practice adoption: Evidence from the literature. J Soil Water Conserv 63(5):300.

Rainie L, Wellman B. 2012 Networked: The New Social Operating System. Cambridge: MIT Press.
Rogers EM. 2010. Diffusion of Innovations (4th ed.). New York: Simon and Schuster.

Ryan B, Gross NC. 1947. The diffusion of hybrid seed corn in two lowa communities. Rural Sociol 8:15-24.

Seger J. 2011. The new digital [st]age: Barriers to the adoption and adaptation of new technologies to deliver Extension programming and how to address them. J Extension 49(1):1FEA1.

[USDA NASS] US Department of Agriculture National Agricultural Statistics Service. 2017. Farm Computer Usage and Ownership. http:// usda.mannlib.cornell.edu/ MannUsda/viewDocumentInfo. do?documentID=1062

Watts DJ. 2004. Six Degrees: The Science of a Connected Age. New York: WW Norton \& Company.

Wejnert B. 2002. Integrating models of diffusion of innovations: A conceptual framework Annu Rev Sociol 28(1):297-326. https://doi.org/10.1146/ annurev.soc.28.110601.141051

Wenger EC, Snyder WM. 2000. Communities of practice: The organizational frontier. Harvard Bus Rev 78(1):139-46. 